\title{
Feasibility trial to assess the patient safety culture in the professional group of dietitians
}

\author{
Sarah Geil ${ }^{1}$, Gerald Sendlhofer ${ }^{2,3^{*}}$, Hermann Toplak' ${ }^{1}$ Gudrun Pregartner ${ }^{4}$, Elisabeth Pail ${ }^{1}$ \\ From Safety in hospitals: from strategy to implementation Annual Scientific Meeting 2015 \\ Graz, Austria. 29-30 September 2015
}

\section{Background}

Patient safety culture is determined by the requirement of understanding of values, attitudes, competences and behavioral patterns [1,2]. Dietitians are health professionals trained to advice on diet, food and nutrition and provide nutrition expertise including nutrition assessment, diet modification and individual or group counselling [3]. Within hospitals, dietitians represent a relatively small professional group. For example, the University Hospital Graz has eleven dietitians and approximately 7,000 employees in total.

The primary aim of this feasibility trial was to assess the perceived patient safety culture solely within the professional group of dietitians. Three hospital organizations from Austria, Germany and Switzerland were invited to participate. To the best of our knowledge this is the first report concerning patient safety culture within the professional group of dietitians.

\section{Material and methods}

ETH Zurich, Center for Organizational and Occupational Sciences (PASKI) translated the HSOPSC survey into German [4]. Survey results are separated into three levels:

- Level 1: 9 dimensions concerning the unit-level

- Level 2: 3 dimensions concerning the hospital-level

- Level 3: 3 Outcome measures

The survey contained 48 questions using the 5-point Likert response scale of agreement. In 2014 a paperpencil feasibility trial was conducted. The questionnaire was sent to 62 nutrition experts (Austria $\mathrm{n}=44$, Germany $n=16$, Switzerland $n=2$ ); the survey was open for one month. The conduct of the online survey

\footnotetext{
* Correspondence: gerald.sendlhofer@klinikum-graz.at

${ }^{2}$ Executive Department for Quality and Risk Management, University Hospital Graz, Graz, Austria

Full list of author information is available at the end of the article
}

was approved by the Medical University Graz Ethics Committee (vote-number: 27-002 ex 14/15).

Survey data were analyzed using descriptive statistics. Internal consistency of the questionnaire and its items was measured by Cronbach's alpha coefficient. Reliability was considered good if values were $>0.7$ and very good if values were $>0.9$. All analyses were conducted using SPSS version 21.

\section{Results}

The overall response rate was $55 \%(\mathrm{n}=18(41 \%)$ from Austria, $\mathrm{n}=14(88 \%)$ from Germany and $\mathrm{n}=2(100 \%)$ from Switzerland). Cronbach alpha coefficient ranged from 0.44 for item "feedback and communication about error" to 0.90 for the item "handoffs and transition across units".

\section{Conclusions}

This feasibility trial was the first attempt to attract the professional group of dietitians in assessing the patient safety culture. So far, the professional group of dietitians had been underrepresented in the literature concerning patient safety culture measurements. The targeted goal to compare three nations was not achieved. As only two dietitians from Switzerland took part, just pooled results are shown. Perceived patient safety culture for almost all items had been good, despite the item of "staffing" and "patient safety in general". This feasibility trial could be supportive to further attract patient safety aspects such as critical incident reporting systems or clinical risk management within the professional group of dietitians.

\section{Competing interests}

The authors declare that they have no competing interests.

\section{Acknowledgements}

The authors would like to thank all participants who took part in this feasibility trial. 
Table 1. Pooled survey results for dietitians from Austria $(n=18)$, Germany $(n=14)$ and Switzerland $(n=2)$

\begin{tabular}{|c|c|c|c|c|c|}
\hline & Mean & SD & Median & Min & Max \\
\hline \multicolumn{6}{|c|}{9 dimensions concerning a unit or department } \\
\hline Manager expectations and actions promoting safety & 4.18 & 0.67 & 4.00 & 2.67 & 5.00 \\
\hline Organizational learning & 4.25 & 0.55 & 4.33 & 3.33 & 5.00 \\
\hline Teamwork within hospital units & 3.92 & 0.65 & 4.00 & 2.50 & 5.00 \\
\hline Communication openness & 3.96 & 0.58 & 4.00 & 2.67 & 5.00 \\
\hline Feedback and error communication & 4.21 & 0.60 & 4.17 & 2.67 & 5.00 \\
\hline Non-punitive response to error & 4.15 & 0.65 & 4.00 & 2.50 & 5.00 \\
\hline Staffing & 2.84 & 0.94 & 2.50 & 1.00 & 5.00 \\
\hline Management support with respect to patient safety & 4.11 & 0.69 & 4.25 & 1.75 & 5.00 \\
\hline Handoffs and transition within the unit & 3.65 & 0.73 & 3.71 & 1.75 & 5.00 \\
\hline \multicolumn{6}{|c|}{3 Outcome measures } \\
\hline Frequency of event reporting & 3.56 & 0.78 & 4.00 & 1.33 & 4.67 \\
\hline Overall perceptions of safety & 4.11 & 0.52 & 4.13 & 3.25 & 5.00 \\
\hline Patient safety in general & 2.17 & 0.45 & 2.00 & 1.00 & 3.00 \\
\hline \multicolumn{6}{|c|}{3 dimensions concerning the hospital } \\
\hline Teamwork across hospital units & 3.78 & 0.57 & 3.75 & 2.50 & 5.00 \\
\hline Handoffs and transition across units & 3.62 & 0.63 & 3.67 & 2.50 & 5.00 \\
\hline Supervisor expectations and actions promoting safety & 4.15 & 0.55 & 4.33 & 2.67 & 5.00 \\
\hline
\end{tabular}

\section{Authors' details}

'Medical University Graz, Graz, Styria, Austria. ${ }^{2}$ Executive Department for Quality and Risk Management, University Hospital Graz, Graz, Austria.

${ }^{3}$ Division of Plastic, Aesthetic and Reconstructive Surgery, Department of Surgery, Medical University of Graz, Graz, Austria. ${ }^{4}$ Institute for Medical Informatics, Statistics and Documentation, Medical University of Graz, Graz, Austria.

Published: 30 October 2015

\section{References}

1. Occelli P, Quenon JL, Kret M, Domeca S, Delaperche F, Claverie O, et al: Validation of the French version of the Hospital Survey on Patient Safety Culture questionnaire. Int J Qual Health Care 2013, 25(4):459-468.

2. Chen IC, Li HH: Measuring patient safety culture in Taiwan using the Hospital Survey on Patient Safety Culture (HSOPSC). BMC Health Serv Res 2010, 10:152.

3. Dietitians make a difference to employee health: Highlights from a systematic literature review of the effectiveness of nutrition counselling. Dietitians of Canada 2009 [http://www.dietitians.ca/Dietitians-Views/HealthCare-System/Primary-Health-Care/Dietitians-make-the-difference.aspx], (Accessed 14 March 2015).

4. Manual zum Patientensicherheitsklima-Inventar (PaSKI): ETH Zürich, Center for Organizational and Occupational Sciences [http://www.beldonor.be/ internet2Prd/groups/public/@public/@dg1/@acutecare/documents/ ie2divers/19066312_de.pdf], (Accessed 15 March 2015).

doi:10.1186/2056-5917-1-S1-A14

Cite this article as: Geil et al:: Feasibility trial to assess the patient safety culture in the professional group of dietitians. Safety in Health 2015 1(Suppl 1):A14.

\section{Submit your next manuscript to BioMed Central and take full advantage of:}

- Convenient online submission

- Thorough peer review

- No space constraints or color figure charges

- Immediate publication on acceptance

- Inclusion in PubMed, CAS, Scopus and Google Scholar

- Research which is freely available for redistribution

Submit your manuscript at www.biomedcentral.com/submit
C Biomed Central 